Dhaka Univ. J. Biol. Sci. 22(2): 179-182, 2013 (July)

- Short communication

\title{
INFLUENCE OF LEGUMINOUS TREES ON SOIL NITROGEN AND PHOSPHORUS STATUS OF THE SAL FORESTS
}

\author{
Mohammad Zabed Hossain*, Tania Sultana, Ashfaque Ahmed \\ AND SirAJul HoQue ${ }^{1}$ \\ Department of Botany, University of Dhaka, Dhaka-1000, Bangladesh
}

Forests are one of the extremely complex and interacting ecosystems on Earth ${ }^{(1,2)}$. It supports diverse biotic communities of plants as producers, animals as consumers and microbes as decomposers. The ecological linkage across these communities occurs through complex networks of biological interactions and ecological processes ${ }^{(3)}$. Plant species identity or plant functional traits play important roles in regulating these processes through litter decomposability and nutrient dynamics ${ }^{(4,5,6)}$.

The Sal (Shorea robusta Roxb. ex Gaertn. f.) forests in Bangladesh is dominated by Sal constituting about $75 \%$ of the total trees $(7)$. Of the 54 families recorded in the forest, Leguminosae was the largest with 24 species under 15 genera $^{(7)}$. Understanding the role of leguminous plants on nutrient cycling is relevant for the management and conservation of the forest. This study attempted to evaluate the role of leguminous plants for the nutritional management of Sal forest in the districts of Gazipur, Tangail and Mymensingh.

Sal stands with and without legume trees were selected near National Park under the district Gazipur. Selected Sal stands with legume tree had at least one legume tree of minimum diameter at breast height (dbh) of $10 \mathrm{~cm}$ and included Butea monosperma, Albizia procera and Acacia auriculiformis. A patch of Sal plants with minimum diameter of $50 \mathrm{~m}$ was considered as a Sal stand. A total of 9 stands, 4 for Sal stands with legume trees and 5 for Sal stands without legume trees, distributed within 2 kilometer from each other, were selected to place quadrats $(8 \mathrm{~m} \times 8 \mathrm{~m})$. Plant species per quadrat were identified and recorded.

Shannon diversity index $(H)$ was determined as follows:

Shannon diversity index $(H)=\sum \mathrm{Pi}(\operatorname{lnPi})$

$$
\mathrm{Pi}=\frac{\text { No. of individuals of a species }}{\text { Total number of individuals of all species }}
$$

In addition, coverage (\%) and Importance Value Index (IVI) were also calculated for each species.

*Author for correspondence: <zabed@du.ac.bd>. ${ }^{1}$ Department of Soil, Water and Environment, University of Dhaka, Dhaka-1000, Bangladesh. 
Soil $(0-10 \mathrm{~cm})$ and leaf samples were collected in triplicate and mixed thoroughly to make a composite sample. $\mathrm{pH}$, moisture, organic matter, nitrogen and phosphorus contents of the soil as well as nitrogen and phosphorus contents of Sal leaf samples were determined by following standard protocols described by Hossain et al.(6). Fresh and fully expanded mature leaves of Sal trees were collected to measure nitrogen and phosphorus contents. Data analyses were performed using JMP 4.0 (SAS Institute Inc., Cary, NC, USA).

Plant species richness was significantly $(\mathrm{p}=0.05)$ higher in Sal stand with legume trees (13.0) than the Sal stand without legume trees (9.4). Shannon diversity index value was also higher in Sal stand with legume (1.88) than that of without legume tree (1.29), although not statistically significant $(\mathrm{p}=0.09)$. In Sal stand with legume tree, the most dominant species Sal alone accounted for $45.8 \%$ and five plant species together accounted for about 70\% coverage. On the other hand, in Sal stand without legume tree, Sal plants alone covered $62.1 \%$ and this species along with Melastoma malabathricum covered about $70 \%$ area. S. robusta covered most of the area of the Sal forest in both Sal stand with and without legume trees. IVI was higher for S. robusta in both Sal stands with and without legume trees. The IVI value accounted for the Sal stand with legume trees was higher (118.1) than that without legume trees (78.6).

Soil $\mathrm{pH}$ in both Sal stands with and without legume trees was found to be acidic (Table 1). Mean soil pH in the Sal stand with and without legume tree was 5.35 and 5.14, respectively, although not statistically significant. Soil moisture content also showed no significant difference between Sal stand with and without legume trees. The mean soil

Table 1. Physico-chemical properties of soil of Sal stands with and without legume trees in the Sal forests, Bangladesh.

\begin{tabular}{lccc}
\hline & Sal stand with legume tree & Sal stand without legume tree & $\mathrm{p}$ \\
\hline $\mathrm{pH}$ & 5.35 & 5.14 & 0.26 \\
Moisture (\%) & 6.22 & 5.84 & 0.66 \\
Organic matter (\%) & 1.172 & 1.069 & 0.41 \\
Nitrogen (\%) & 0.006 & 0.005 & 0.19 \\
Phosphorus (\%) & 0.005 & 0.003 & 0.02 \\
\hline
\end{tabular}

moisture content in Sal stands with and without legume trees were 6.23 and 5.84\%, respectively. Mean soil organic carbon in Sal stand with legume tree was $0.68 \%$ and that in the Sal stand without legume tree was $0.62 \%$, although no significant difference appeared. The mean soil organic matter and total nitrogen in Sal stand with legume tree were 1.172 and $0.006 \%$ and in Sal stand without legume tree it was 1.069 and $0.005 \%$, respectively showing no significant difference. Soil phosphorus content was significantly $(\mathrm{p}=0.02)$ higher in Sal stand with legume $(0.005 \%)$ than that without legume tree $(0.003 \%)$ (Table 1$)$. 
The mean nitrogen and phosphorus contents in Sal leaf in Sal stand with legume tree were 0.97 and $0.113 \%$ and those in the Sal stand without legume tree were 0.96 and $0.108 \%$, respectively showing no significant difference. Sal leaf nitrogen content showed no significant correlation with either soil nitrogen and phosphorus content, however, Sal leaf phosphorus content showed a significant positive correlation with the soil nitrogen content $(\mathrm{r}=0.738, \mathrm{p}=0.02)$ (Table 2$)$.

Table 2. Correlation coefficients $(r)$ between nitrogen $(N)$ and phosphorus $(P)$ contents of soil and Sal leaf.

\begin{tabular}{lcc}
\hline & $\mathrm{r}$ & $\mathrm{p}$ \\
\hline Soil N vs Sal leaf N & 0.348 & 0.359 \\
Soil N vs Sal leaf P & 0.738 & 0.023 \\
Soil P vs Sal leaf N & 0.081 & 0.837 \\
Soil P vs Sal leaf P & -0.300 & 0.432 \\
Sal leaf N vs Sal leaf P & 0.644 & 0.061 \\
\hline
\end{tabular}

Wild legumes are widely distributed in forest ecosystems and actively contribute to soil fertility in the natural ecosystems ${ }^{(8)}$. They enhance the nitrogen input of forest through biological nitrogen fixation which is required by the plants for their growth (9). Data obtained in the present study revealed that leguminous plants have the potential to enrich soil nutrients in the Sal forest ecosystem. Significantly higher soil phosphorus content in the Sal stand with legume trees than that of without legume trees was most probably due to increased leaf phosphorus content of the legume plants that provide soil with phosphorus. Studies have shown that leguminous plants have close association with mycorrhizal fungi and are dependent on mycorrhiza for phosphorus(10). The symbiotic mycorrhizal structures can tap a larger volume of soil than the nonmycorrhizal roots, thus gaining advantages in absorbing phosphorus ${ }^{(11)}$. A significant positive correlation of phosphorus content of Sal leaf litter with soil nitrogen content but not with soil phosphorus content indicates that uptake of phosphorus in Sal plants is dependent not only on the availability of soil phosphorus but also on the availability of nitrogen in soil. Over all, the result of the present study indicates that leguminous plants can influence soil nutrient status of the Sal forest. Result of the present study is thus relevant for the nutritional management of the Sal forest.

\section{References}

1. Freedman B 1989. Harvesting of forest. In: Environment Ecology. Academic Press, Inc. San Diego, California. pp. 225-246.

2. Subba TB 2010. The Forest Ecological Foundation. In: Forest Ecosystem in Modern World. G. S. Rawat for Cyber Tech. Publications. New Delhi, India. pp. 141-191. 
3. Naeem S, M Loreau and P Inchausti 2002. Biodiversity and ecosystem functioning: the emergence of a synthetic ecological framework. In: Loreau M, S Naeem and P Inchausti (Eds). Biodiversity and Ecosystem Functioning. Synthesis and Perspective. Oxford University Press, Oxford, 3-11.

4. Hobbie SE 1992. Effects of plant species on nutrient cycling. Trend Ecol. Evol. 7: 336-339.

5. Cornelissen JHC 1996. An experimental comparison of leaf decomposition of temperate plant species and types. J. Ecol. 84: 573-582.

6. Hossain MZ, O Atsushi and S Sugiyama 2010. Effects of grassland species on decomposition of litter and soil microbial communities. Ecol. Res. 25: 255-261.

7. Malaker JC, MM Rahman, AKMA Prodhan, SK Malaker and MAH Khan 2010. Floristic composition of Madhupur Sal forest in Bangladesh. J. Soil Nature 4(1): 25-33.

8. Zahran HH 2001. Rhizobia from wild legumes: diversity, taxonomy, ecology, nitrogen fixation and biotechnology. J. Biotech. 91: 143-153.

9. Edmonds RL, D Binkley, MC Feller, P Sollins, A Abee and DD Myrold 1989. Nutrient cycling effects on productivity of northwest forests. In: Perry DA (and others) eds. Maintaining the long-term productivity of pacific northwest forest ecosystems. Portland, OR: Timber Press: 17-35.

10. Scheublin TR, RSPV Logtestijn and MGAVD Heijden 2007. Presence and identity of arbuscular mycorrhizal fungi influence competitive interactions between plant species. J. Ecol. 95: 631- 638.

11. Bolan NS 1991. A critical review on the role of mycorrhizal fungi in the uptake of phosphorus by plants. Plant Soil. 134: 189-207. 